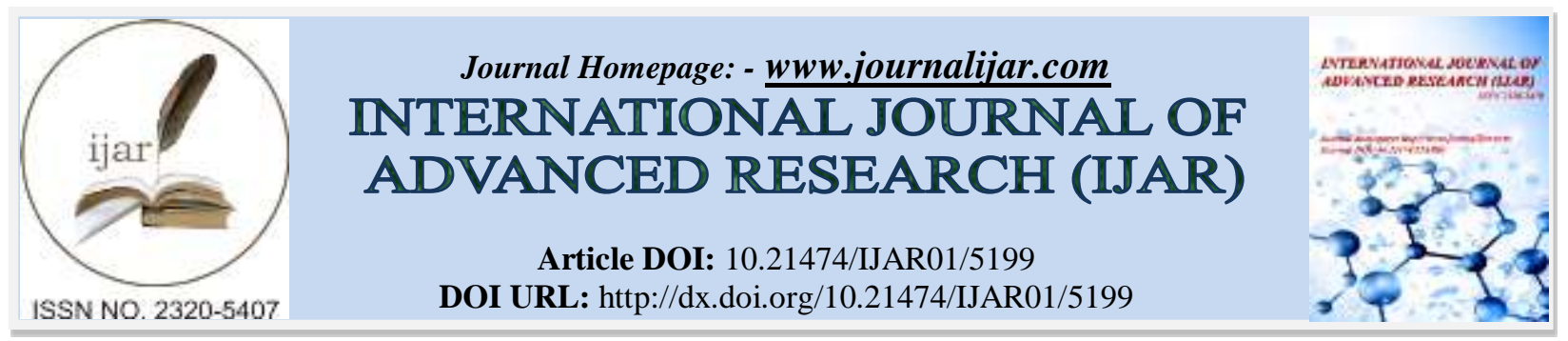

RESEARCH ARTICLE

\title{
REMOVAL OF CUPRIC IONS IN AQUEOUS SOLUTION BY ADSORPTION ON BARKS OF DACRYODES EDULIS AND MANGIFERA INDICA.
}

\author{
Martin Tchoumou ${ }^{1}$, Kimbassa Mahoungou Fréderic Guenol ${ }^{1}$ and Mouelet Cédric ${ }^{2}$. \\ 1. Faculty of Sciences and Technology, University Marien NGOUABI, Brazzaville, CONGO. \\ 2. Normal Superior School, University Marien NGOUABI, Brazzaville, CONGO.
}

\section{Manuscript Info}

Manuscript History

Received: 17 June 2017

Final Accepted: 19 July 2017

Published: August 2017

Key words:-

Adsorption - mangifera indica dacryodes edulis - adsoption isotherm maximamum adsorption capacity.

\begin{abstract}
The adsorption of the cupric ions on bark of dacryodes edulis and mangifera indica was studied under various experimental conditions with an aqueous solution of concentration $63,55 \mathrm{mg} / \mathrm{L}$. The effect of adsorbent dosage, the contact time and the $\mathrm{pH}$ of solution was examined. In all cases, the percentage of adsorbed metal increases with the contact time and the adsorbent dosage; it takes two hours of contact time to reach equilibrium with the bark of mangifera indica, whereas one needs of them three hours for those of dacryodes edulis.

On the other hand, the effect of $\mathrm{pH}$ on the percentage of adsorbed metal is not the same in both cases since the maximum adsorption on the bark of mangifera indica is located between $\mathrm{pH} 5$ and 6, whereas with the bark of dacryodes edulis, the $\mathrm{pH}$ is higher than 6 .

The results obtained showed that the bark of mangifera indica adsorbed the quantities of copper larger than those of dacryodes edulis; the maximum adsorption capacity determined by the interpretation of the model of Langmuir isotherms are $5,85 \mathrm{mg} / \mathrm{g}$ for the bark of mangifera indica, and $5,22 \mathrm{mg} / \mathrm{g}$ for those of dacryodes eludis.
\end{abstract}

Copy Right, IJAR, 2017,. All rights reserved.

\section{Introduction:-}

Industrial development caused these last years the increase in the quantities of the liquid effluents charged in heavy metals in many countries which it is necessary to reject into the receiving medium. If these effluents are not treated before their rejection, they can

the disappearance of certain plants and animals species (Mounia et al., 2012 ; Patil et al., 2012).

Several methods of elimination of heavy

with costs and outputs various according

metals in aqueous solution are

generate

The most used methods are chemical precipitation, solvent extraction, electrolysis and adsorption (Azzoug et al., 2010 ; Rengaraj et al., 2002)

These last years, the adsorption of the inorganic pollutants is the object of several studies; the activated carbon is the adsorbent one more used but it is too expensive (Rahangdale et al., 2017; Mahmoud et al., 2014)

In recent years, many studies have been carried out using the natural adsorbents less expensive and largely available in the developing countries like the wood barks, the algae, the sugarcane bagasse ( Mohammed et al., 2016 ; Nidhi Jain 2015 ; Ali Mcheik et al., 2016) 
However, the use of the natural adsorbents is not yet well optimized on a large scale for various reasons among which, the diversity of vegetable material and need for treating them chemically to increase their adsorption capacity( Montes et al., 2003 ; Prapti et al., 2015). The adsorption of the ions in aqueous solution brings into play reactions of different nature, but several authors are of agreement on the fact that the most important are the reactions of ion exchange and complexation (Meral et al., 2012). The adsorption of the ions is influenced by several parameters among which $\mathrm{pH}$, the contact time, the adsorbent dosage, the initial concentration of the pollutant and the temperature (Naveen et al., 2014 ; $\quad$ Ruiti et al., 2015). The modeling of adsorption equilibrium is based the isotherms of adsorption which translate the relations between the quantity of adsorbed metal and that remained in solution. Several models of the isotherms are used but within the frame work of this work, only the model of Langmuir was used to determine the maximum adsorption capacity (Mohamed et al., 2011 ; Omrannand Mosstafa 2015).

This work is a comparative study of the elimination of the cupric ions in aqueous adsorption on barks of abundantly finds in Brazzaville, Republic of CONGO. edulis which are fruit solution by trees that one

\section{Materials and methods:-}

The barks of mangifera indica and dacryodes edulis were collected from trees in a district of Brazzaville in Republic of CONGO. These barks were washed with the tap water and dried in sunlight during three weeks, then dried in an oven with $105^{\circ} \mathrm{C}$ during three hours before being crushed and filtered until a granulometry of $75 \mu \mathrm{m}$.

Before their use as adsorbent, they were washed with the distilled water at a quantity of $50 \quad \mathrm{~g}$ in $2 \quad$ liters under agitation during three hours in order to eliminate the residues of crushing and the organic compounds likely to color the solution and to disturb the determination of cupric ions using spectrophotometric method (Bandela et al.,2016).

The stock solution containing the cupric ions was prepared by dissolving a given quantity of $\mathrm{Cu}\left(\mathrm{NO}_{3}\right)_{2}, 6 \mathrm{H}_{2} \mathrm{O}$ in distilled water and the desired solution with the concentration of $63.55 \mathrm{mg} / \mathrm{L}$ was obtained by dilution.

The contact of the adsorbent with the solution of cupric ions was ourried in beakers of $100 \mathrm{ml}$ containing $50 \mathrm{ml}$ of cupric ions under agitation and various experimental conditions; After separation of the mixture adsorbent / solution by filtration, the cupric ions were analyzed with a spectrophotometer Aqualytic AL 800, with the method of the calibration curve (Nassima and Moussa, 2010). The equilibrium adsorption capacity $\mathrm{qe}(\mathrm{mg} / \mathrm{g})$ was determined by the following relation wavelength of $800 \mathrm{~nm}$ by using the

$$
\mathrm{qe}=\frac{(\mathrm{Ci}-\mathrm{Ce}) \mathrm{V}}{m}
$$

With:

$$
\begin{aligned}
& \text { Ci: } \\
& \text { Ce: } \\
& \text { V: }
\end{aligned}
$$

m:

equilibrium

The percentage of adsorbed metal is

$$
\% \text { adsorbed Metal }=\frac{(\mathrm{Ci}-\mathrm{Ce}) 100}{\mathrm{Ci}}
$$

The parameters studied during this study are The $\mathrm{pH}$ of the solution was or with those of $\mathrm{NaOH} 0.1 \mathrm{~mol} / \mathrm{L}$ (Bhat et al.,2013) The Langmuir model of the isotherms the $\mathrm{pH}$, the contact time and the adsorbent dosage. adjusted either with a solution of $\mathrm{HCl} 0.1 \quad \mathrm{~mol} / \mathrm{L}$, adsorption capacity using the linear relation (Malarvizhi et al.,2013).

$$
\frac{1}{q e}=\frac{1}{q \max }+\frac{1}{q \max C e b}
$$

with:

qe

$$
\mathrm{q}_{\max }:
$$

maximum equilibrium

adsorption
adsorption mass of the adsorbent in grams initial concentration of the ion in $\mathrm{mg} / \mathrm{L}$ concentration of the ion in $\mathrm{mg} / \mathrm{L}$ volume of the solution in liters calculated by the following relation: determine the maximum 
Ce: $\quad$ equilibrium $\quad$ concentration (mg/L)

b: Langmuir constant ( $\mathrm{L} / \mathrm{mg})$

The intercept of the curve expressing the variations of $1 / \mathrm{qe} \quad$ as function of makes it possible to determine $\mathbf{q}_{\max }$ and the slope makes it possible to determine the Langmuir equilibrium constant b

The separation factor

$$
\mathrm{R}_{\mathrm{L}}=\frac{1}{1+b C i} \text {. }
$$

was used to know if adsorption is favorable or unfavorable (Ackacha and Meftah, 2014).

\section{Results and discussion:-}

Influence of the adsorbent dosage on the percentage of adsorption:-

The percentage of the adsorbed metal as function of the adsorbent dosage is represented by the figure 1 .

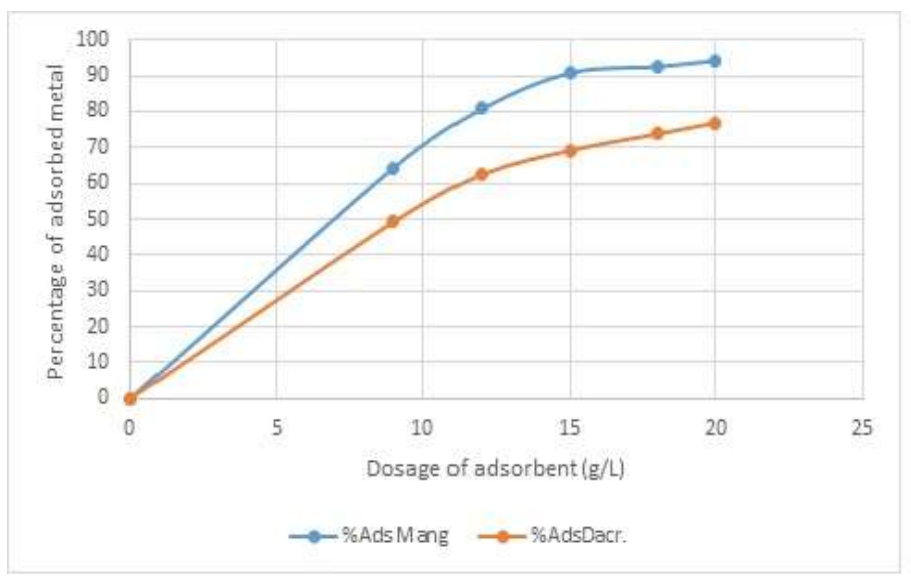

Figure 1:- Influence of the adsorbent dosage on the percentage of the adsorbed metal

This curve shows that the percentage of adsorbed metal increases much more with the barks of mangifera indica that with those of dacroydes The adsorbent dosage necessary to reach equilibrium solution of cupric ions for the two adsorbents. with the adsorbent

dosage edulis.

This increase in the percentage of the adsorbed metal with the adsorbent dosage can be explained by an increase of active surface and thus amongst sites of adsorption (Abdellaoui et al., 2014).

Indeed, an increase in the adsorbent dosage involves that amongst sites of adsorption; but as is held the phenomenon of adsorption, the occupation of the first sites of adsorption makes increasingly difficult the adsorption of the ions and that involves a reduction the reaction speed of adsorption which results in the existence of a stage on the curve (Torab-Mostaedi et al.,2010)

Influence of the contact time on the percentage of adsorbed metal:-

The adsorption of metal in aqueous solution depends on the contact time. The Figure 2 represents the variations of the percentage of the adsorbed metal on each adsorbent as function of the contact time. 


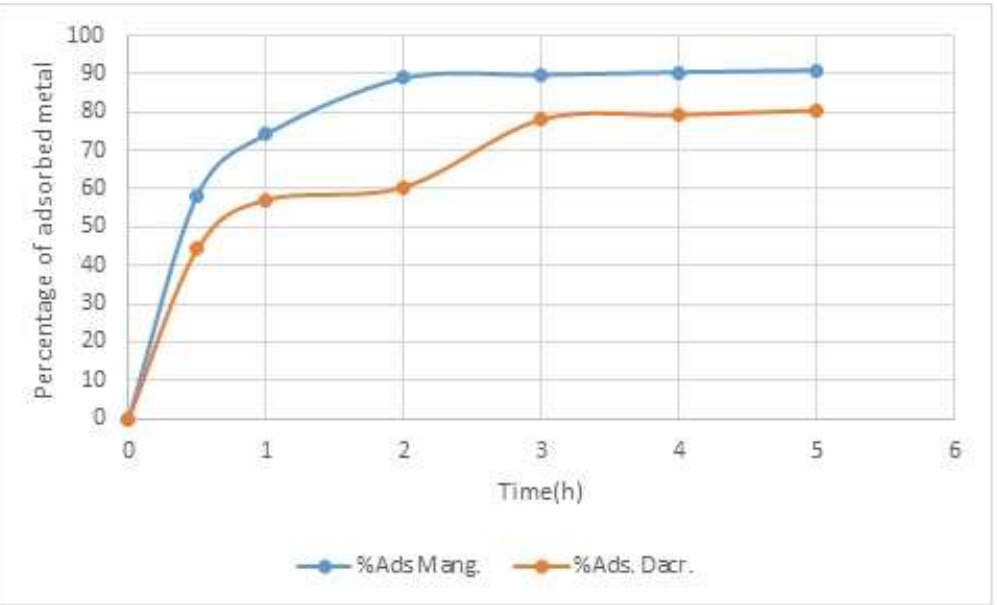

Figure 2:- Influence of the contact time on the percentage of adsorbed metal

This curve shows that in each case, It takes two hours of contact time the speed is

to reach the fast at the beginning and decrease with time. equilibrium of adsorption with the barks of

mangifera indica whereas one needs of them three hours with the barks of dacryodes edulis. When equilibrium is reached, the percentage of the adsorbed metal on the barks of mangifera indica is higher than that obtained on the barks of

dacryodes edulis.

This difference can be explained amongst other things by the chemical composition and properties which are not the same for the two adsorbents, in particular the number of adsorption sites and specific surface.

Influence of the $\mathrm{pH}$ on the percentage of adsorption:-

The effect of the $\mathrm{pH}$ was studied in the interval from 2 to 6 for a contact time of two hours; the maximum value of the $\mathrm{pH}$ equal to 6 was retained to avoid the precipitation of the cupric ions which would be likely to cause an interaction between the phenomena of adsorption and precipitation of $\mathrm{Cu}(\mathrm{OH})_{2}$ (Ackacha and Meftah, 2014).

The figure 3 shows the variations of the percentage of the adsorbed metal as function of the $\mathrm{pH}$ of the solution for each adsorbent.

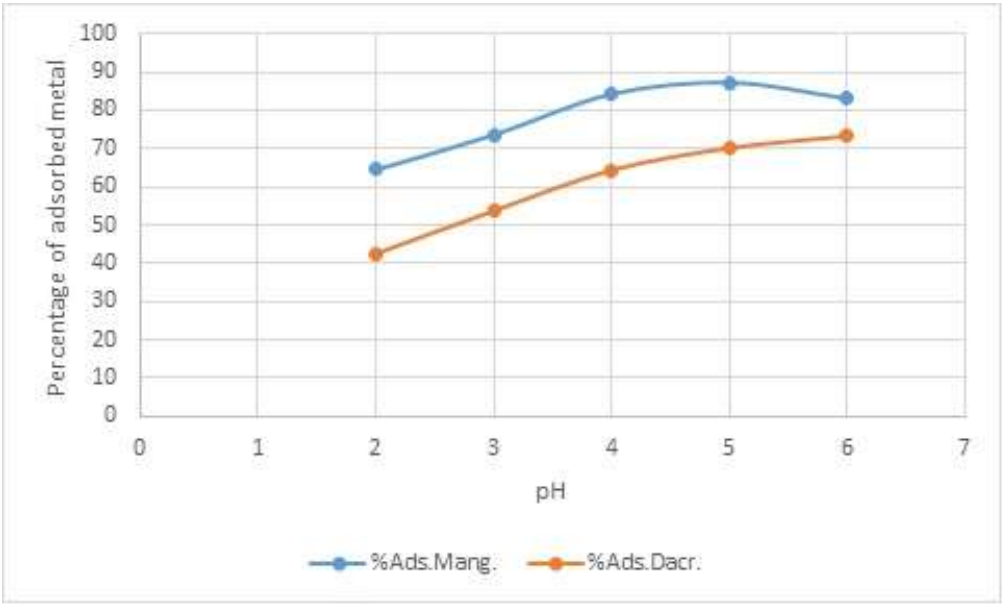

Figure 3:- Influence of the $\mathrm{pH}$ on the percentage of adsorption of metal

This figure shows that the percentage of a maximum between $\mathrm{pH} 5$ and 6 on the barks Similar results were adsorption of the cupric already ions on announced by other authors. Ferrocene, Qian et al., of

At (2013) reach

\section{mangifera indica.} the time of a study of the obtained similar variations 
to those which we obtained on interactions between the species surface of the adsorbent. In ions $\mathrm{Cr}(\mathrm{VI})$ on vegetable materials and allocated this variation by the existence of the electrostatic forces between the surface of the adsorbent and the various species charged with chromium present in the solution according to the $\mathrm{pH}$. Indeed, according to the $\mathrm{pH}$ of the solution, the particles of the adsorbent can be charged negatively or positively so as to have effects on the electrostatic attraction forces between the ion and the adsorbent (Kumar et al.,2014). On the other hand, this percentage does not pass by a maximum with the barks of dacroydes edulis

We think that this difference in behavior of the explained by the fact that they do

not

have the

$\mathrm{Cu}^{2+}$ ions on the two adsorbents can be same surface

properties.

\section{Determination of the maximum adsorption capacity:-}

The determination of the maximum adsorption linear relation of the Langmuir isotherm. capacity was

carried Figure 4 represents the variations of 1/qe of 1/Ce obtained during the adsorption of the cupric ions on the barks of mangifera indica

mangifera indica and these authors explain the variation by at the the

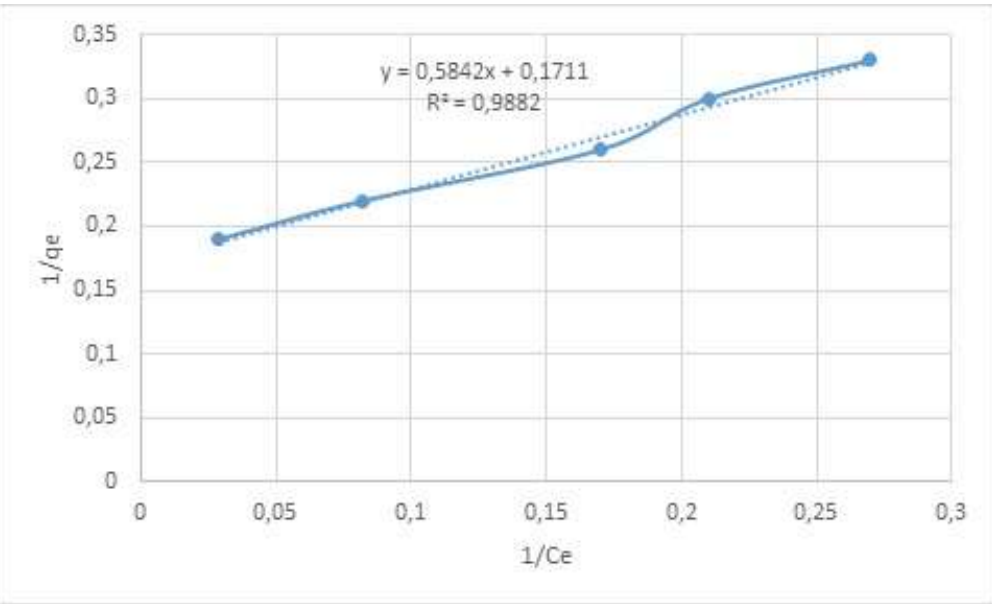

Figure 4:- Langmuir Isotherms for adsorption of cupric ions on mangifera indica

This curve gives the intercept equal to 0.1711 and a slope equal to 0.5842 which made it possible respectively to determine the maximum adsorption $\mathrm{q}_{\max }=5.85 \mathrm{mg} / \mathrm{g}$ and the Langmuir equilibrium

The figure 5 represents the variations of $1 / \mathrm{qe}$ as adsorption of the cupric ions on the barks of dacroydes eludis

function

capacity $\mathrm{b}=0.29 \mathrm{~L} / \mathrm{mg}$. of $1 / \mathrm{Ce}$ obtained during the ent

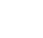

.




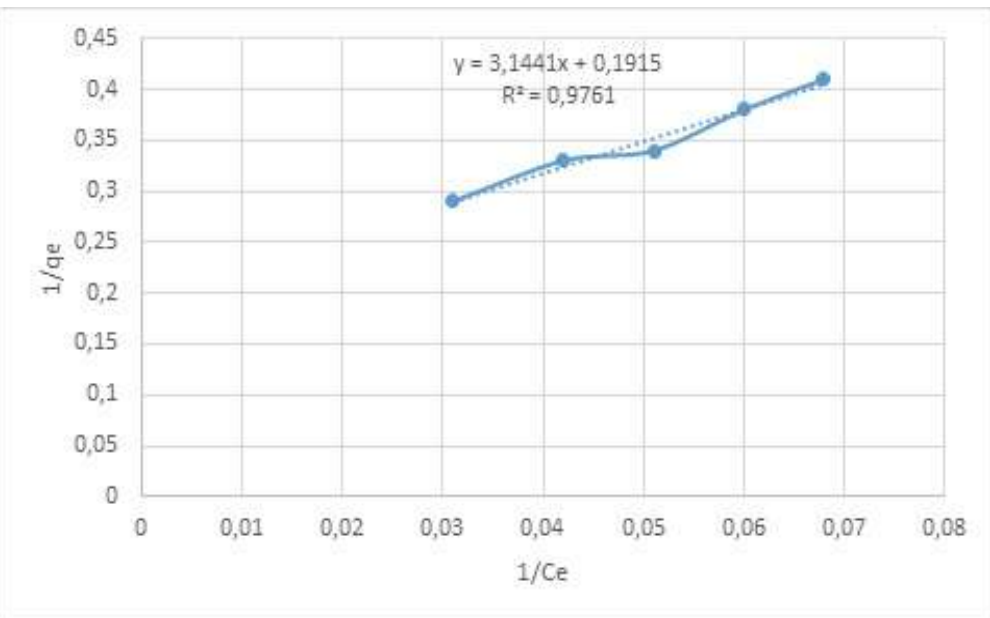

Figure5:- Langmuir Isotherms for adsorption of cupric ions on dacroydes edulis

In the same way, the maximum adsorption capacity on dacroydes edulis is $\mathrm{q}_{\max }=5.22 \mathrm{mg} / \mathrm{g}$ and the constant of equilibrium of Langmuir $b=0.06 \mathrm{~L} / \mathrm{mg}$

The comparison of the maximum adsorption capacities shows that the barks of indica adsorb more cupric ions in aqueous solution although the difference is Compared with the results of the quantities of cupric ions. For capacity of the cupric ions in literature, these two adsorbents do not example, Ragwan et al., aqueous solution on the not important. great adsorption powder of palm nuts of $76.2 \mathrm{mg} / \mathrm{g}$.

All parameters determined by the exploitation of the model of Langmuir isotherms are given in the table I

Table I:- Langmuir Parameters

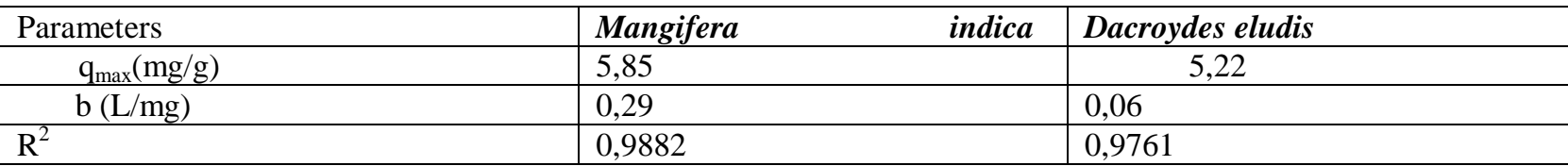

The separation factor $R_{L}$ have values equal to 0.05 and 0.20 respectively for

on the barks of mangifera indica and dacroydes edulis; these values higher than zero indicate that the adsorption of the cupric ions on these two adsorbents is favorable.

\section{Conclusion:-}

The objective of this work was to study the possibility of eliminating the cupric ions in aqueous solution by adsorption on barks of mangifera indica and

dacryodes edulis.

The results obtained showed that these two adsorbents can be used to adsorb cupric ions
in aqueous solution, although the nol too large when on them compared to other adsorbents. The percentage of adsorbed metal is function oh $\mathrm{pH}$; contact time and adsorbent dosage.

In both cases, the contact time between the solution and the adsorbent to reach equilibrium is two to three hours according to the adsorbent whereas the best percentage of adsorption is obtained between pH 5 and $6 . \quad$ The percentage of absorbed metal is higher on the barks of mangifera indica compared to those of dacryodes edulis

The determination of the maximum adsorption Langmuir isotherms gave $\quad 5.85$ and capacities by the exploitation of the indica and dacryodes edulis

The value of the separation factor higher $5.22 \mathrm{mg} / \mathrm{g}$ respectively on the barks of mangifera adsorption of the cupric ions is favorable on these two adsorbents. than zero in both cases indicated that the 


\section{Acknowdgement:-}

The authors thank the University Marien NGOUBI for Brazzaville to

have

placed at their

disposal equipment and the reagents having allowed the realization of this work.

\section{References:-}

1. Abdellaoui, S. EL Hani, R. Bengueddour , H. El Hassouni, D.(2014)

Biosorption of cadmium(II) and copper(II) from aqueous solution using red alga (Osmundea pinnatifida) biomass, J. Mat. Environ. Sci.,5(4), 967-974.

2. Ackacha M. A and Meftah S.A (2014)

Accaciac Tortilis Seeds as a Green Chemistry Adsorbent to clean up the water from Cadmium cation, Int. J. Environ. Sci. Dev. 5(4), 375 - 379.

3. Ali Mcheik, Wassef EL Khatib, Akram Hijazi , Kamal Hariri, Mohamed Reda and Hassan Rammal (2016)

Removal of heavy metals from waste water by using a natural and biodegradable adsorbent based on PRUNUS AVIUM L. STEMS as adsorbent, Int. J. Adv. Res., 4(12), $441-449$.

4. Azzoug S, , Arous O., and H. Kerdjoudj H. (2010),

Extraction liquide-liquide et transport facilité du plomb (II) et du cadmium (II) par le tribytyl-phosphate et le tris-ethyl-hexyl phosphate, J. Soc. Alg. Chim., 20(2), 73 - 82.

5. Bandela N. N, Babrekar M.G., Jogdan O.K. and Geetanjali Kaushik (2016)

Removal of Copper from aqueous solution using local agricultural wastes as low cost adsorbent, J. Mat. Environ. Sci., 7(6), 1972-1978.

6. Bhat Irshad U. H, Elias Nursafura B and Khanam Zakia (2013)

Adsorption Studies of Cr (VI) and Fe (II) in Aqueous Solutions Using Rubber Tree Leaves as an Adsorbent, Int. Res. J. Environ. Sci., 2(12), 52-56.

7. Ksakas A. Loqman A., Bali B. E., Taleb M. andKherbeche A. (2015)

The adsorption of $\mathrm{Cr}$ (VI) from aqueous solution by natural materials, J. Mat. Environ. Sci., 6(7), 2003-2012.

8. Kumar S, Mishra A.K., Upadhyay M., Singh D., Mishra M. and Kumar S. (2014)

Kinetic, Thermodynamic and Equilibrium Study on Removal of Lead(II) from Aqueous Solution Using Fly Ash, Int. Res. J. Environ. Sci., 3(2), 83-92.

9. Mahmoud T., Nassima B., Salem. And Hassina G. (2014)

Préparation et caractérisation d'un charbon actif à partir de la coquille d'amande (Prunus amygdalus) amère, Biotechnol. Agron. Soc. Environ., 18(4), 492-502.

10. Malarvizhi T.S., Santhi T. and Manonmani S.(2013)

A Comparative Study of Modified Lignite Fly Ash for the Adsorption of Nickel from Aqueous Solution by Column and Batch Mode Study, Res. J. Chem. Sci., 3(2), 44-53.

11. Meral Y. and Ayhan Ş.(2012)

Adsorption and desorption behavior of silver ions onto valonia tannin resin, Trans. of Nonfer. Met. Soc. China, 22, 2846-2854.

12. Mohamed C. and Fouad S. (2011)

Élimination des ions $\mathrm{Cu}(\mathrm{II})$ d'une solution aqueuse par les micro-particules de la plante Carpobrotus edulis en système dynamique, Wat. Qual. Res. J. Can., 46(3), 259-267.

13. Mohammad A. L., Syed K. A.and Sana S.(2016)

The Remediation of Wastewater by Adsorption on an Agro-based Waste, Int. J. Environ. Prot., 6(1), 81-89.

14. Montes S. , Valero G., Morales S., Vilches A.M. and Schmidt R.(2003)

Adsorption capacity of copper of natural and modified radiate bark pine, J. Chil. Chem. Soc., 48(4), 1-14.

15. Mounia EL Haji, Boutaleb S., Lamarti R. and Larej L.(2012)

Qualité des eaux de surface et souterraine de la région de Taza (Maroc) : bilan et situation des eaux, Afri. Sci. , $8(1), 67$ - 78.

16. Nassima T. and Moussa A. (2010)

Adsorption du Cr (VI) sur la lignine activée, Rev. Wat. Sci. 23(3) 233-245.

17. Naveen D., Chandrajit B. and Prasenjit M.(2014) 
Study for the treatment of Cyanide bearing Wastewater using Bioadsorbent Prunus Amygdalus (Almond shell): Effect of $\mathrm{pH}$, adsorbent dose, Contact Time, Temperature, and initial Cyanide concentration, Int. Res. J. Environ. Sci., 3(1), 23-30.

18. Nidhi J. (2015)

Removal of heavy metal by using different fruit peels, vegetable peels and organic waste. A review; Int. J. Adv. Res. 3(11), $916-920$.

19. Omran A. and Mosstafa K. (2015)

A review study of biosorption of heavy metal and comparison between different biosorbent, J. Mat. Environ. Sci. 6(5), $1386-1399$.

20. Patil K. P., Vilas S., Nilesh P. and Motiraya V. (2012)

Adsorption of Copper $\left(\mathrm{Cu}^{2+}\right)$ and Zinc $\left(\mathrm{Zn}^{2+}\right)$ Metal Ion from Waste Water by Using Soybean Hulls and Sugarcane Bagasse as Adsorbent, Int. J. Sci. Res. Rev.,1(2),13-23.

21. Prapti U. S. Nirav P R. and Nisha K. S. (2015)

Adsorption of copper from aqueous solution by chemical modified cassava starch J. Mat. Environ. Sci. 6(9) 2573 - 2582.

22. Qian W., Senlin T., Zongliang H., Jiaqi Li, and Ping N.(2013)

Adsorption Characteristics of Copper (II) onto Ferrocene Modified Resin Int. J. Environ. Sci. Dev., 4(2), 130- 133.

23. Ragwan M., Alaa M., and Mohamed E. (2016)

Biosorption of $\mathrm{Cr}(\mathrm{VI})$ and $\mathrm{Cu}(\mathrm{II})$ by Palm Kernel Powder and Its Potential Application, Int. J. Environ. Sci. Dev., 7(11), 788-792.

24. Rahangdale P. K. Donaldkar D. K and Gour K (2017)

Removal of carcinogic hexavalent chromium from contamined water using activated carbon derived from BOMBAX CEIBA Bark, Int. J. Adv. Res. 5(6), 204-209.

25. Rengaraj S. , Kyeong-Ho Yeon, So-Young K., Jong-Un Lee, Kyung-Woong Kim, and Seung-Hyeon Moon (2002),

Studies on adsorptive removal of $\mathrm{Co}(\mathrm{II}), \mathrm{Cr}(\mathrm{III})$ and $\mathrm{Ni}(\mathrm{II})$ by IRN77 cation-exchange resin, J. Haz. Mat.., B92 , 185-198.

26. Ruiti M. and Bechir B. T. (2015),

Elimination of iron by processes of oxidation and by adsorption on coal pine, Int. J. Innov. Appl. Studies, 10(2), 694-700.

27. Torab-Mostaedi M., Ghassabzadeh H., Ghannadi-Maragheh M., Ahmadi S. J. and Taheri H. (2010), Removal of cadmium and nickel from aqueous solution using expanded perlite,

Braz. J. Chem. Eng., 27(2) 299 - 308. 